\title{
Industry 4.0 as a Key Enabler toward Successful Implementation of Total Quality Management Practices
}

\author{
Sami Sader ${ }^{1 *}$, István Husti², Miklós Daróczi² \\ 1 Doctoral School of Mechanical Engineering, Szent Istvan University, \\ H-2100 Gödöllő, Páter Karoly. Street 1., Hungary \\ 2 Institute of Engineering Management, Faculty of Mechanical Engineering, Szent Istvan University, \\ H-2100 Gödöllő, Páter Karoly Street 1., Hungary \\ * Corresponding author, e-mail: sami.s.a.sader@phd.uni-szie.hu
}

Received: 15 June 2018, Accepted: 27 April 2019, Published online: 07 August 2019

\begin{abstract}
Industry 4.0 refers to the new technological development occurred at the industrial production systems. It evolved as a result of integrating Internet of Things, Cyber-Physical Systems, Big-Data, Artificial Intelligence, and Cloud Computing in the industrial systems. This integration aided new capabilities to achieve a higher level of business excellence, efficiency, and effectiveness. Total Quality Management (TQM) is a managerial approach to achieve an outstanding business excellence. There are several approaches to apply TQM principles at any organization. Industry 4.0 could be utilized as a key enabler for TQM especially by integrating its techniques with the TQM best practices. This paper suggests a theoretical framework for integrating Industry 4.0 features with the TQM principles (according to ISO 9000:2015 standards family) in order to open the door for further research to address the real impact of utilizing Industry 4.0 for serving the TQM implementation approaches.
\end{abstract}

Keywords

Industry 4.0, Total Quality Management, Quality 4.0, business excellence

\section{Introduction}

It's obvious the impact of recent technological development and the advancement of human's life at every field. Life has never been interconnected and collaborated as much as it became nowadays. Modern technologies and platforms such as social media, Internet of Things (IoT), Cloud Computing (CC), Artificial Intelligence (AI) and Cyber-Physical Systems (CPS) led to great leaps in many fields such as industry. New industrial concepts came onboard representing the recent developments in industry as a response to the advancements of relevant technologies. Accordingly, Industry 4.0 became a new industrial concept that increasingly becoming an important widely discussed subject in many researches.

Industry 4.0 is known as the technological development occurred in industry from embedded systems to intelligent Cyber-Physical Systems (MacDougall, 2013). It was firstly suggested and adopted by the German Government in its High-Tech Strategy 2020 (MacDougall, 2013), introduced in 2011 during the Hannover fair event (Qin et al., 2016). Industry 4.0 aims at utilizing the new technological systems such as Internet of Things, Cloud Computing, and Big-Data to revolutionize the industry to an intelligent manufacturing systems (Trappey et al., 2017), where production facilities and warehousing facilities are connected to each other in the form of Cyber Physical Systems (Kagermann et al., 2013).

The name (Industry 4.0) stands for the fourth industrial revolution. As illustrated in Fig. 1, the first three revolutions represent the development of industry since the first revolution, emerged during the 18th century, and relied on mechanical power generated from steam and water. The second revolution, emerged during the 20th century, advanced the industry to mass production lines, where production process was divided into stages, building on the experience of labor gained from the repeated work, responding to the increased market demand. This period was characterized by using conveyors to transfer products between machines automatically. The third revolution came as a result of integrating the programmable logic controllers (PLC), which were invented during the 


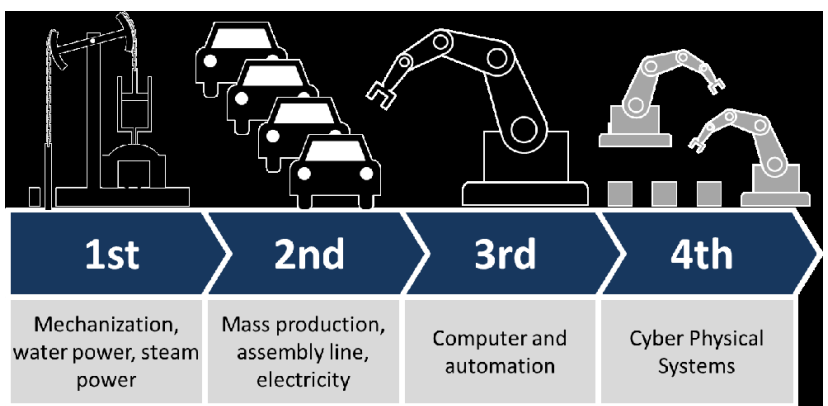

Fig. 1 Illustration of Industry 4.0, showing the four "industrial revolutions" (Source: Christoph Roser: http://www.allaboutlean.com)

1970s and facilitated the automation of industrial production, and minimized the efforts needed by labor. Recently, the computer systems were developed and integrated in the industry, this utilization was developed until IoT was brought to stage and launched the new fourth industrial revolution which was agreed to be known as Industry 4.0 (Brettel et al., 2014; MacDougall, 2013; Qin et al., 2016).

The need for Industry 4.0 came from the fact that $17 \%$ of the GDP generated in the European countries is accumulated from industry, offering 32 million job positions. However, this large economical sector in Europe, is being challenged by the aging community of the EU countries, and concurrently, the accelerating development of other competing industrial economies such as China, Asia and other developing countries (Qin et al., 2016). Accordingly, Industry 4.0 was innovated and supported by the German Government in order to maintain the leading industrial position of Germany (MacDougall, 2013).

Supported by the recent development of smart IT solutions including data gathering devices (sensors), and intelligent analysis systems (software and cloud computing), Industry 4.0 provided the ability to analyze big-data, resulted and gathered while production and during the whole value chain, translate it to a user-friendly information, replacing the traditional monitoring and decision-making strategies, and providing a key enabler for industrial effectiveness and efficiency. Hence, a bedrock for Industry 4.0 development (Kagermann et al., 2013).

Industry 4.0 came to respond to the increasing demand for innovative solutions in production and logistics, producers are focusing on creating greater value for customers, who are becoming more aware and advanced demanders for reliable, personalized and high-quality products (Witkowski, 2017). Industrial businesses are seeking more competitive position through acquiring flexible production lines, zero inventory, efficient resources allocation, high responsiveness to market demand, lower logistic and labor costs, and to acquire more competitive advantages above other competitors (Rennung et al., 2016; Wang et al., 2017).

Industry 4.0 is expected to have a profound impact on business excellence, effectiveness and efficiency. There are many researchers who addressed the role of Industry 4.0 in many perspectives.

The aim of this paper is to discuss the role of Industry 4.0 in developing Total Quality Management practices. Firstly, a review for the features, technologies and capabilities of Industry 4.0 is presented. Then, major TQM practices are explored, and finally, the TQM practices are discussed from the context of Industry 4.0, hence, how Industry 4.0 will influence the implementation of TQM principles (pros and cons). And finally, the paper will conclude the results of this research work and will propose future relevant research topics.

\section{Methodology of this study}

To realize the objective of this paper, the following methodology was followed:

- Firstly, reviewing Industry 4.0 major features, tools and capabilities.

- Secondly, analyzing the TQM best practices and the critical success factors that have a proven impact on product's quality, customer satisfaction and business excellence.

- Then, highlighting the opportunities where Industry 4.0 can support the best implementation of these success factors and hence, improving the quality of products and the overall business excellence, and highlight some new challenges for TQM in the context of Industry 4.0.

- As a further step, a new Industry 4.0 based TQM conception will be proposed for further studies, where every element of this conception is supported by the features of Industry 4.0. Other research opportunities have been suggested for further studies and analysis.

\section{Industry 4.0}

The production strategy depends presently on mass production to minimize the production cost per-unit, and to fulfill the expanding market demand of a product (economies of scale). However, in the recent decade, customers are increasingly demanding more than ever before, looking for more customized and detailed products that differs from each other (Brette et al., 2014; Wang et al., 2017). Industry 4.0 opened the door for more customized 
products, preserving mass production and fulfilling advanced customers' requirements at the same time.

Industry 4.0 changed the production traditional production from a centralized to a de-centralized regime, made it possible to advance the production from a traditional machining process to a more interactive and complex process where the product can communicate with the machine, informing it what to do (Kagermann et al., 2013). Additionally, the support of intelligent CPS provided the ability of the machine to gather data, analyze, learn, and decide independently (Lee et al., 2015). This feature paved the way to a brand-new industrial generation, where factories are intelligent enough, having the ability of self-planning and self-adapting in order to provide more customized products and fulfilling the customer expectations autonomously (Witkowski, 2017).

Industry 4.0 occupies a significant importance nowadays not only for its economic benefits, but also to respond to new technological advancement, driven by:

- The accelerating growth of data volumes, cloud computing and artificial intelligence technologies, improved connectivity and the capability to analyze large volume of operational data at advanced levels in real-time which were not possible before.

- The need for more advanced analysis of data on products, markets and customers. The more analytical capabilities are existing, the higher would be the quality of products. Analyzing customers' requirements and returning feedback is important to maintain the customer satisfaction. Thus, strong, ongoing and reliable analytics are required.

- The newly introduced Human-to-Machine (H2M) and Machine-to-Machine (M2M) interaction capabilities, the development of augmented reality, touch surface and other hands-free operating systems.

- The advancement of technologies needed for industry, such as robotics, 3D printing, and digital data transfer.

As summerized in Fig. 2, Industry 4.0 is characterized by three key features; Interconnection, Integration, and Big-Data:

- Interconnection is the core feature of Industry 4.0, where all kinds of machines doing various jobs are interconnected together, forming an intelligent digitized value chain, where the product can hold readable information (RFID) that can be understood by machines, thus, the machines can process the product, and when it is needed, it can re-adjust, diagnose, and repair production tactics until achieving an optimal situation (Zhou et al., 2015). The basis of Industry 4.0 is the ability to exchange data and information among the value chain in real time, all instances involved in the value chain are connected and data is accumulated (Husti et al., 2017).

- Integration is the ability of Industry 4.0 to perform vertical, horizontal and end-to-end integration. Vertical Integration refers to the networked smart business units; e.g.: smart factory, smart logistics, smart marketing, and services (Mrugalska and Wyrwicka, 2017), where manufacturing units are coordinating and communicating smoothly. Horizontal Integration over the value chain, refers to the forward to backward (customer to supplier) integration. Horizontal Integration enabled the manufacturing environment to become collaborative during the stages from development to production, resulting more efficient, reliable and effective manufacturing. End-to-End integration is the overall integration of the entire production regime, performing a decentralized system where all participating entities have realtime access to information and control is distributed to the production floor instantly (Brettel et al., 2014).

- Big-Data: The rapid development of internet and networking, produced huge volume of information that requires innovative methods and tools to handle (Blanchet et al., 2014). Big Data and cloud computing granted the ability to conduct quick and efficient management for the constantly growing databases (Lee et al., 2014).

Based on these features, Industry 4.0 is expected to support the following capabilities of a production system:

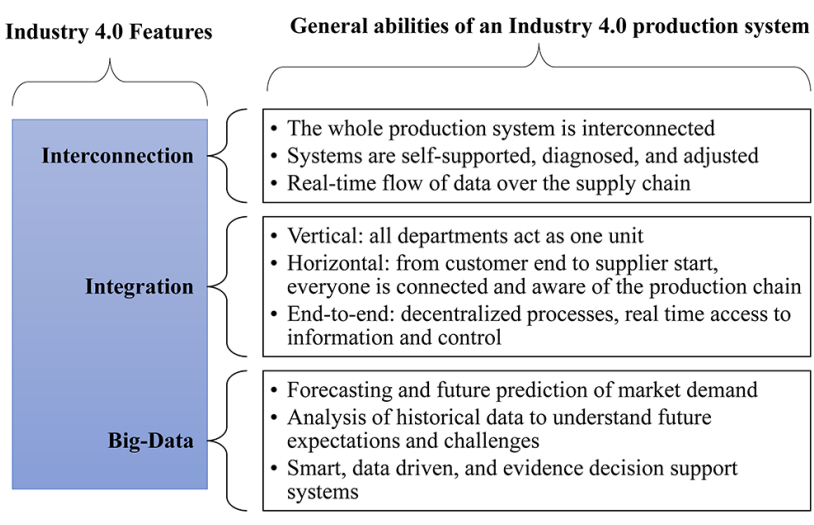

Fig. 2 Features and abilities of Industry 4.0 (Source: self-developed according to literature) 
- Ability to improve communication and collaboration among the value chain of a production system from customers end to suppliers and vice-versa.

- Creating a responsive production system that fulfils market demand quantitatively and qualitatively in a very responsive manner. The new Industry 4.0 production systems can respond to customer's expectations and technical requirements and improve products simultaneously (Wang et al., 2017).

- Achieving high effectiveness and efficiency of production systems (improved resources allocation, selective human intervention, automatically optimized production planning, improved supply chain management) (Witkowski, 2017).

- Advanced quality assurance, introducing modern "intelligent quality control systems", early failure prediction system, cost-effective quality monitoring techniques (Kuo et al., 2017).

- Lean production system, where all kinds of waste including time, materials, human power, and inventory level are in optimum values (Mrugalska and Wyrwicka, 2017).

- Transparent production system, where every activity is clearly represented, monitored, recorded and assessed in real-time.

\section{Total Quality Management (TQM)}

TQM is a managerial approach that leads an organization to achieve a world-class position by ensuring that its products and services satisfy customers by meeting their requirements and expectations (Yusof and Aspinwall, 2000). The Term "Total Quality Management" was first suggested and led by the American scientist Edwards Deming (19001993), who traveled from the United States of America to Japan to help the Japanese industrial firms to recover from the World War II. During his work, he implemented the statistical quality control and process control, as tools to trace production errors and to identify the source of products' defects (Kanji, 1990). Later, he met with Joseph Juran (1904-2008), who was stressing to focus on customers' satisfaction through producing fit-to-use products that fulfills the customers' needs. Shortly, both Deming and Juran successfully caught the attention of markets all over the world, their innovative ideas increased the production rates in Japan, and contributed very strongly to the Japanese wellknown successful industrial miracle (Kanji, 1990).

Since then, the philosophy of TQM has been enhanced and expanded, several TQM principles and practices were suggested to guide the good implementation of TQM at organizations. The goal was to benefit business stakeholders, where every personnel at the organization as well as the business processes are cooperating to produce valuefor-money products and services that fulfil and exceed the customers' expectations (Dale, 2015). Researchers found strong evidences that TQM has improved the organizational effectiveness, flexibility, competitiveness, excellence, created positive attitude, and created continuous improvement culture at the organization (Anil and Satish, 2016).

There is no explicit universal approach to implement TQM (Anil and Satish, 2016). However, Yusof and Aspinwall (1999) agreed that TQM critical success factors are those "must be practiced in order to achieve an effective quality management system". Accordingly, after a comprehensive literature review for the most known TQM "gurus" (such as Juran, Crosby, Deming, Ishikawa, and Feigenbaum), Quality Awards (such as the American Malcom Baldrige National Quality Award, European Quality (EFQM) Award, and Deming Prize), and empirical researches, Anil and Satish (2016) concluded 18 critical success factors that were agreed to be the most critical factors for successful TQM implementation, they suggested the comprehensive list in Table 1.

In addition to these success factors, the international standard organization model, known as (ISO 9000 standard family), maintained and updated by the International Standards Organization, is a very popular and widely utilized model as a reliable, effective, and efficient approach to realize TQM. The recent ISO 9000 family standards version was updated in 2015 and known as ISO 9000:2015.

ISO 9000:2015 specified $7 \mathrm{TQM}$ principles to achieve TQM (ISO, 2015a). These principles are: (1) customer focus, (2) leadership, (3) engagement of people, (4) process approach, (5) improvement, (6) evidence-based

Table 1 TQM Critical success factors

\begin{tabular}{ccc}
\hline $\begin{array}{c}\text { Leadership and } \\
\text { top management } \\
\text { commitment } \\
\text { Continuous } \\
\text { improvement } \\
\begin{array}{c}\text { Supplier quality } \\
\text { management }\end{array}\end{array}$ & $\begin{array}{c}\text { Education and } \\
\text { training }\end{array}$ & Quality culture \\
Strategic & management & Benchmarking \\
Customer focus & Quality information process & Process and product \\
analysis & Process management \\
Employees & Quality assurance & Product Innovation \\
involvement & Quality citizenship & Knowledge \\
Employees & management \\
\hline empowerment & 2016) &
\end{tabular}


decision making, and (7) relationship management (ISO, 2015b). Accordingly, to make this research more precise, this paper will analyze the requirements of the ISO 9001:2015 quality management system and will suggest the opportunities, and challenges of TQM in the context of Industry 4.0. These general principles can exhibit most of the success factors that are listed in Table 1. For example, the fourth ISO 9000:2015 principle which is "process approach" can also refer to: process management, statistical process control, and process and product design. This can be confirmed based on the interpretation of each item as explained in the ISO 9000:2015 fundamentals and vocabulary document (ISO, 2015c). Fig. 3 illustrates the hierarchy of the ISO quality management system principles and the TQM implementation.

Moreover, it is important to discuss "Quality Control" and "Quality Assurance" as these are important practices toward TQM. The goal of all the approaches is to implement TQM which finally aims to satisfy customers and realize business excellence through effectiveness and efficiency.

\section{TQM in the context of Industry 4.0}

Based on the previous discussions, and the identification of the TQM principles according to ISO 9000: 2015, this chapter aims at finding the area where Industry 4.0 can serve the successful implementation of the TQM principles, quality control, and quality assurance. The following analysis established the connection between TQM and Industry 4.0 based on matching the ISO 9001:2015 requirements and Industry 4.0 features and tools. The analysis suggesting a balanced view where opportunities and challenges are brought together to the table and discussed from an ideal point of view. The following discussion suggests the means of support Industry 4.0 can offer to TQM implementation practices; a summary of this discussion is illustrated in Fig. 4:

- Customer Focus: as per the ISO 9000:2015 fundamentals and vocabulary (ISO, 2015c), Customer focus as an approach to TQM aims to show the commitment of the organization leadership to fulfill, and to strive to exceed customers' needs and expectations, ensuring consistency with regulatory requirements and statutory, identifying risks and opportunities that can affect customers conformity of use and customer satisfaction, ensuring that customer focus approach is sustained and continuously maintained. Accordingly, this paper suggests that Industry 4.0 will

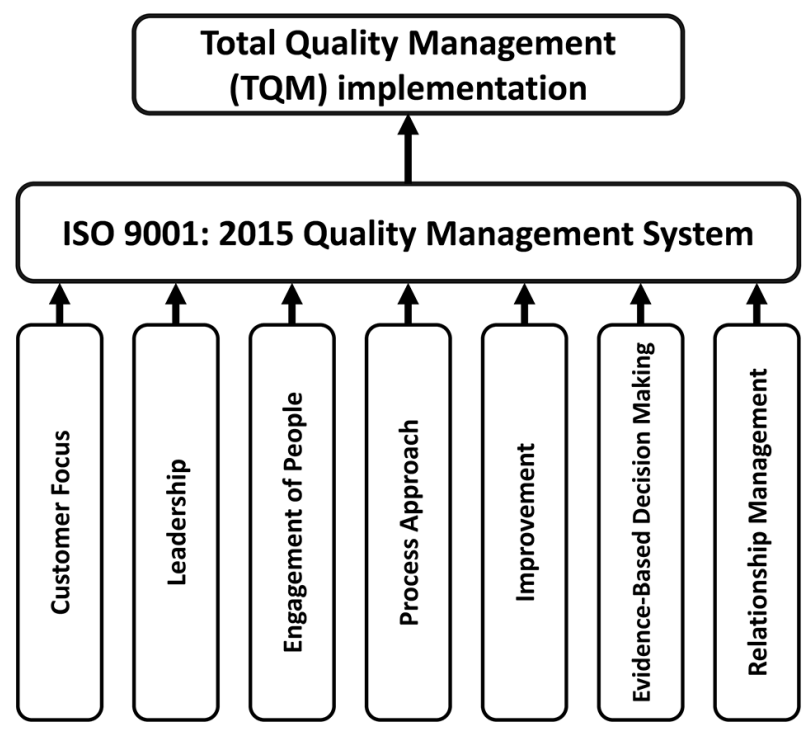

Fig. 3 ISO 9001:2015 principles and TQM implementation (Source: self-developed according to literature)

enable organizations to improve their customers' satisfaction through improving the quality of the delivered products and services, due to intensive quality control and quality assurance practices. Additionally, Industry 4.0 will enable companies to produce and deliver "individual customized" products and services at a regular time, away from the complexity of amending the mass production regimes. Therefore, customers will be served on an individual basis, which will consequently improve customers' satisfaction and conforming their quality expectations. Moreover, Industry 4.0 connectivity features will involve customers in the production process by providing means of communications before, during, and after the production process, allowing them to be part of the production process, rather than only being the recipient of it. Other features like Big-Data analysis will boost the ability of the company to early predict market demand and consumption trends and changes, thus, increasing responsiveness by providing proper products at the proper time.

- Leadership: Leadership aims at establishing unity of purpose where people inside a firm are involved in achieving the quality objectives of the company. This will enable the company to align strategies, policies, processes, and resources to realize the quality objectives (ISO, 2015c). Industry 4.0 features such as "Vertical, Horizontal, and End-to-End integrations", Enterprise Resources Planning (ERP) systems, Big-Data analysis, and high connectivity 


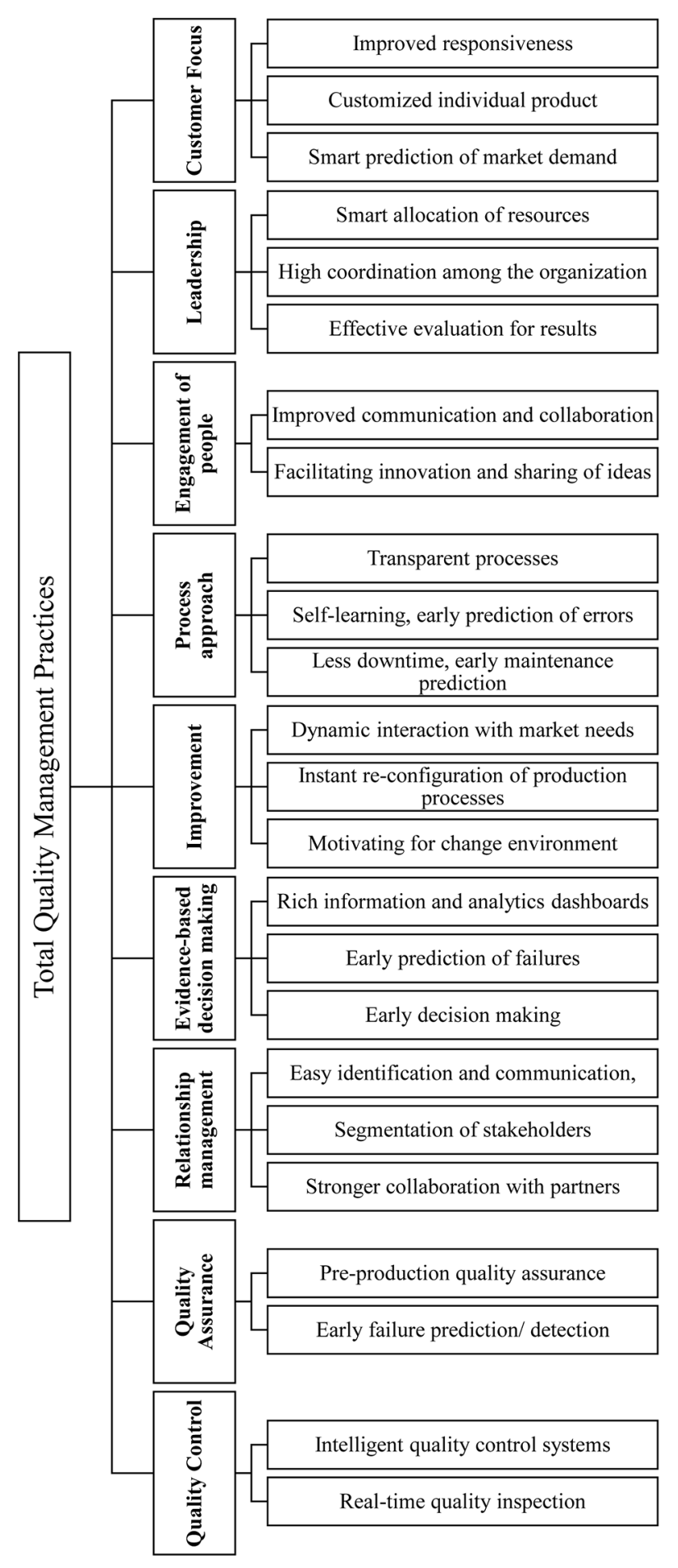

Fig. 4 Total Quality Management in the context of Industry 4.0 (Source: self-developed according to literature)

technologies, facilitated leadership tasks by enhancing coordination and collaboration among different leadership levels, which in total improved the capability of the company to deliver distinctive quality results. Evidences showed that Industry 4.0 had a great impact on information flow over the production chain, integrating the business processes and supporting the ERP systems to optimize manufacturing management (Lee et al., 2014). Industry 4.0 provided transparent production processes, thus, supported the leadership capabilities to align and optimize resources such as labor and machines to fulfill demand efficiently and effectively.

- Engagement of people: A successful Quality Management System (QMS) encompasses that people at all levels inside the organization are engaged and participating in boosting the organization's capabilities to create and deliver value to customers (ISO, 2015c). Within such context, Industry 4.0 will support the communication and collaboration among all people inside the organization providing different means of people engagement and human resources management benefiting from connectivity features and social networking. Moreover, Industry 4.0 will stimulate innovation, by encouraging individual contribution to the development of the organization. Utilizing Industry 4.0 tools such as Big-Data analysis, ERP systems, Artificial Intelligence, and instant interpretation of data to knowledge and information, will help people at their respective positions to use this knowledge to avoid risks and suggest virtually developed and tested solutions, hence, be more initiative and creative. Industry 4.0 changed the role of workers from being "machine operators" to a higher position by supervising the work while it is being done by the machine (which is called now the Augmented Operator). It is important to mention the Industry 4.0 does not mean a full replacement of people inside the organization. Brettel et al. (2014) suggested that future work of labor will remain irreplaceable, but its content will be changed from the position of doing the work to a more coordinating position where workers must be more skilled in decision making and problem solving especially in dealing with unforeseen problems.

- Process approach: ISO (2015c) stated that effective and efficient business processes are achieved when activities are understood and managed as interrelated and consistent. Optimized system performance can be realized by defining the intended results and how they are produced. Accordingly, Industry 4.0 will support the transparency of business and production processes, it will aid processes' optimization, improve efficiency and resources allocation. 
Industry 4.0 will facilitate tracing production bottleneck, defects' sources, and minimize production cost. Additionally, it will improve the supply chain responsiveness, through total integration from market demand back to suppliers (Wang et al., 2017). Industry 4.0 will provide accurate information about processes (time, risks, resources, critical constraints) among all aspects of production. Thus, it will help the planning level of key-processes to maintain continuity and efficiency (Wang et al., 2017). Moreover, Cyber-Physical Systems will simulate the possible production scenarios according to production dynamic parameters, and then will operate at the optimum scenario. This will minimize the time required to design and test the production regime and will improve process flexibility. Within an Industry 4.0 integrated QMS, quality objectives are defined and aligned with processes objectives (supported by ERP systems, business integration, smooth flow of information between all managerial and production levels). Which will provide solid base to define and align authorities, responsibilities and accountability means needed to manage the processes.

- Improvement: One of the objectives of a QMS is to ensure the commitment of the organization toward continuous improvement of its processes, products and services to enhance customer satisfaction. This entails more focus on root cause analysis and to suggest prevention and remedy actions whenever is needed (ISO, 2015c). Industry 4.0 will provide a basis for continuous improvements at the product, process and business performance for an organization. Totally integrated production system will improve the value chain performance and the responsiveness of the entire system. Moreover, many industries (such as automobile industry) attaching smart devices that can send raw data from the vehicle to the companies' data center containing vehicle performance during operation, thus, reporting any operating issues and, thus, enhancing future products to overcome such issues. Additionally, Industry 4.0 features such as $\mathrm{AI}$ and machine learning will enable the industrial system to detect or early predict machine failures or defective products at early stages and can provide instant root cause analysis as well as instant recommendations of proper remediation. Such advantage will improve the use of learning for improvement and will enhance the ability to anticipate and react to different kinds of risks and opportunities. Such advantages are key benefits to maintain the process of continuous improvement and will open the door for further innovations.

- Evidence-based decision-making: ISO fundamentals and vocabulary document (2015c) stated that desired results are more likely to be reached by decisions taken based on accurate data and information. Industry 4.0 and the linked IT solutions such as Big-Data, AI and Cloud Computing, afforded great opportunity to improve the decision-making process, by providing accurate data and information with useful tools such as business dashboards, to support real-time monitoring, measuring, and determining the organization's performance. Moreover, at the shop-floor level, machines are self-learned (supported by AI and machine learning technologies), connected to each other forming a collaborative community, collecting and analyzing data, providing ability to make independent, self-optimized, autonomous, and instant decisions ( $\mathrm{Lu}$, 2017). Experiments show that Industry 4.0 techniques could send earlier prognostics about machine health, reducing downtime and afford maintenance on time. However, although new technologies minimized the need for people competency in data analysis, as the system will do this job, but the human experience will remain needed in order to make decisions balanced with experience and human intuition.

- Relationship management: in a sustainable QMS, interested parties at any organization are key factors to obtain and retain success, where all interests (opportunities and constraints) are being shared and informed between parties (ISO, 2015a). The aim for managing partnerships as an approach to achieve TQM, is to optimize the production supply chain and to guarantee smooth and stable flow of products and services to customers. Thus, ensuring the highest coordination with production parties and stakeholders (such as: suppliers, patterners, customers, investors). Accordingly, Horizontal, Vertical, and End-to-End integration among the entire business units, plus the effective communication and collaboration tools between all stakeholders within an organization, and modern communication systems under the umbrella of Industry 4.0 provided a great advantage in terms of relationship management with business partners. Suppliers are instantly connected with production systems, promptly notified for the supply 
demand, which in return resulted a responsive supply chain that responds effectively to market needs and decreases the time to market, hence, enhancing customer satisfaction (Brettel et al., 2014).

- Quality Assurance: An Industry 4.0 integrated production system will ensure that all requirements to produce high quality products are fulfilled. The smart machine, smart factory, and augmented operator will define and eliminate the root causes of production defects and will make an instant early action to avoid defects, and production failure. Industry 4.0 will aid processes' optimization, improve efficiency and resources allocation, minimize the efforts needed for quality issues by using sensors at each production stage, and provide means to support quality activities which will result minimizing rework and scrape (Foidl and Felderer, 2016). Big-data analysis will collect real-time data generated during production, transform it to friendly useful information that is readable and accessible by different business units and levels. Such knowledge will be useful to enhance the production systems. Machines can send early notifications for predictive maintenance in advance, avoid downtime or system failure.

- Quality Control: Intelligent quality control systems are widely used nowadays, replacing the traditional quality control techniques like statistical quality control and statistical sampling. Utilizing sensors and real time inspection technologies enabled instant defective products' exclusion, not only for a sample of products but to the overall population of production. Furthermore, intelligent quality control systems are operating at every stage during the production, thus, the cost of quality is minimized as production defects will be early detected, and root causes will be early analyzed and resolved.

In contrast, although this paper highlighted the opportunities offered by Industry 4.0 to quality management, which obviously is the main course of this paper, but it is important to highlight the other ambiguous zones (threats and challenges) within the same context (quality management in the context of Industry 4.0) where quality management can't be fully served by Industry 4.0 features, due to Industry 4.0 challenges and difficulties such as: "scientific, technological, economic, social and political challenges" (Zhou et al., 2015), or where there are barriers to achieve the full advantage of Industry 4.0 to TQM.
As a matter of fact, there is always barriers to apply new technologies in the industry, Albers et al. (2016) summarized few studies which highlighted difficulties of applying Industry 4.0 and related technologies at small and medium companies in Germany. These difficulties were due to knowledge (know-how) and organizational barriers. As a result of such studies Albers et al. (2016) suggested a procedure to lead the change to an intelligent QMS by defining quality objectives based on analyzing the current state of quality and defining the intended targets for the quality management and stakeholders.

Moreover, although automation will enhance the connectivity between customers and organization but there are some tasks that are irreplaceable due to the fact that these jobs need face-to-face interaction (Arntz et al., 2016), hence, dealing with customers before, during and after sale could be one of such tasks, which implies that although Industry 4.0 will support some "customer focus" activities but some other activities are difficult to substitute.

This also can be generalized to other QM activities, such as leadership, process approach and decision-making, where human cumulative experience is needed to conclude from the rich information and data analysis flowing from smart technologies. However, the quality of skills and tasks required to handle such development is also changing to a higher level of experience (Acemoglu and Autor, 2011), where higher skilled people are required at more advanced job positions, and new learning and training outcomes are intended to fill the gap of demanded skills and expertise (Autor, 2015).

In addition to the abovementioned challenges, cyber-security and data protection is also one of the most important challenges to Industry 4.0 (Blanchet et al., 2014; Pereira and Romero, 2017). Lu (2017) highlighted the limitations of customers' involvement in decision making related to products' customization and quality needs (which is more dependent on IoT and Industry 4.0 technologies), resulting from security threats and complexity of human-to-machine interaction. These challenges should also be considered in the ongoing context (TQM and Industry 4.0). What will be the impact of data privacy and security on quality issues? And how to maintain the flow of information related to quality management avoiding the data loss or inaccuracy? Therefore, mitigation plans should be developed to deal with such threats and challenges.

Finally, it is also important to define a set of specific quantitative measures as evidence to describe the actual impact of Industry 4.0 on TQM practices. For instance, 
what is the resulted quantitative change when applying Industry 4.0 at an industrial company in terms of customer satisfaction, improvement of products and processes, cost of quality, efficiency and effectiveness of processes and leadership, decision-making process, and after all the improvement of the overall business results?

\section{Conclusion and suggestions for further research}

This paper highlighted the seven TQM principles identified by ISO 9001:2015 model along with quality control and quality assurance as key principles and practices to implement TQM from an Industry 4.0 perspective.

Industry 4.0 provided a stone rock support for a successful implementation of TQM principles. This paper highlighted the zone where TQM can benefit from Industry 4.0 features. Fig. 5 shows the wider perspective as suggested by this paper to integrate Industry 4.0 features with Total Quality Management practices where Interconnectivity, Integration, and Big-Data can enhance the implementation of quality management approaches.

Within an integrated Industry 4.0 - TQM regime, customers' expectations, market analysis, will be directly communicated to the production systems, products' quality is controlled and assured using smart sensors and failure investigation analysis. Machines are connected, smart, and can predict and plan under different circumstances. Production schemes are flexible and dynamic due to hiring Cyber-Physical Systems, where customized products can be produced without production delay. Suppliers are instantly informed about inventory consumption and can fulfill demand just in time. ERP systems can plan activities and handle orders and other business activities. Quality cost is at its minimum due to smart failure detection and early prediction. All the business units are performing as one integrated unit, where every business unit is a ware and can participate positively to the entire system.

\section{References}

Acemoglu, D., Autor, D. (2011) "Chapter 12 - Skills, Tasks and Technologies: Implications for Employment and Earnings", In: Card, D., Ashenfelter, O. (eds.) Handbook of Labor Economics, Vol. 4, Elsevier, Cambridge, MA, USA, pp. 1043-1171. https://doi.org/10.1016/S0169-7218(11)02410-5

Albers, A., Gladysz, B., Pinner, T., Butenko, V., Stürmlinger, T. (2016) "Procedure for Defining the System of Objectives in the Initial Phase of an Industry 4.0 Project Focusing on Intelligent Quality Control Systems", Procedia CIRP, 52, pp. 262-267. https://doi.org/10.1016/j.procir.2016.07.067

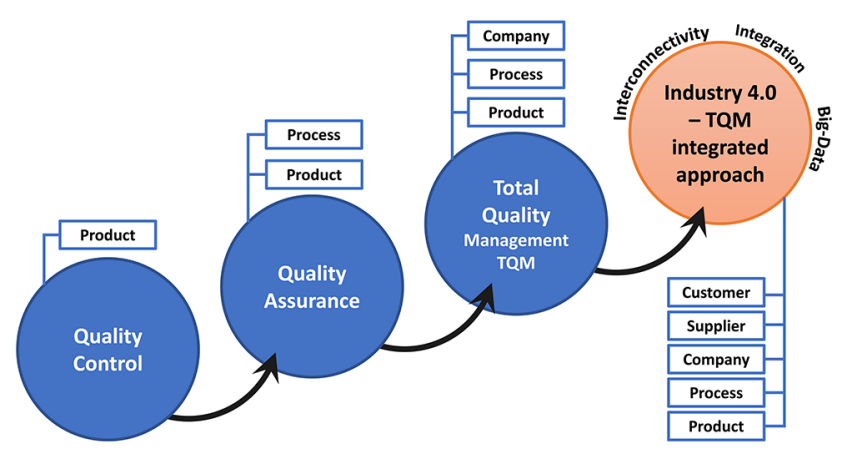

Fig. 5 Integrated Industry 4.0 - Total Quality Management framework (Source: self-developed according to literature)

Within such scenarios, implications of Industry 4.0 are expected to reach an outstanding position of business excellence, effectiveness and efficiency, and at the end a successful implementation of Total Quality Management principles.

Finally, this paper matched the possibilities offered by Industry 4.0 to support the implementation of TQM from a theoretical perspective. Hence, it is very important to use quantitative methods to evaluate the real impact of utilizing Industry 4.0 to support TQM practices, finding an effective interface where Industry 4.0 can influence TQM. Accordingly, this paper suggests future research works to discuss the impact and the role of Industry 4.0 on TQM practices and results. An industrial partnership is highly recommended to ensure good implementation of TQM principles through obtaining ISO 9001:2015 and jointly developing Industry 4.0-based quality management system at the organization.

\section{Acknowledgement}

This work was supported by the Stipendium Hungaricum Programme and by the Mechanical Engineering Doctoral School, Szent István University, Gödöllő, Hungary.

Anil, A. P., Satish, K. P. (2016) "Investigating the Relationship Between TQM Practices and Firm's Performance: A Conceptual Framework for Indian Organizations", Procedia Technology, 24, pp. 554-561. https://doi.org/10.1016/j.protcy.2016.05.103

Arntz, M., Gregory, T., Zierahn, U. (2016) "The Risk of Automation for Jobs in OECD Countries: A Comparative Analysi", OECD Social, Employment and Migration Working Papers, No. 189, OECD Publishing, Paris.

https://oi.org/10.1787/5jlz9h56dvq7-en 
Autor, D. H. (2015) "Why Are There Still So Many Jobs? The History and Future of Workplace Automation", Journal of Economic Perspectives, 29(3), pp. 3-30. https://doi.org/10.1257/jep.29.3.3

Blanchet, M., Rinn, T., von Thaden, G., De Thieulloy, G. (2014) "Industry 4.0: The new industrial revolution, How Europe will succeed", Roland Berger Strategy Consultants GMBH, Munich, Germany. [online] Available at: http://www.iberglobal.com/files/ Roland_Berger_Industry.pdf [Accessed: 15 November 2017]

Brettel, M., Friederichsen, N., Keller, M., Rosenberg, M. (2014) "How Virtualization, Decentrazliation and Network Building Change the Manufacturing Landscape: An Industry 4.0 Perspective", International Journal of Information and Communication Engineering, 8(1), pp. 37-44.

Dale, B. (2015) "Total Quality Management", In: Cooper, C. L., Roden, S., Lewis, M.,Slack, N. (eds.) Wiley Encyclopedia of Management, Wiley, Chichester, UK, pp. 1-4. https://doi.org/10.1002/9781118785317.weom100042

Foidl, H., Felderer, M. (2016) "Research Challenges of Industry 4.0 for Quality Management", In: Felderer, M., Piazolo, F., Ortner, W., Brehm, L., Hof, H.-J. (eds.) Innovations in Enterprise Information Systems Management and Engineering, Springer International Publishing, Cham, Switzerland, 2015, pp. 121-137. https://doi.org/10.1007/978-3-319-32799-0_10

Husti, I., Daróczi, M., Kovács, I. (2017) "Messages from “Industry 4.0” to agriculture", In: Nyéki, A. (ed.) Towards Sustainable Agriculture and Biosystems Engineering, Universiteas-Gyor Nonprofit Ltd., Mosonmagyaróvár, Hungary, pp. 63-78.

International Organization for Standardization Central Secretariat, ISO (2015a) "Quality Management", [pdf] ISO, Geneva, Switzerland, Available at: https://www.iso.org/files/live/sites/isoorg/files/ archive/pdf/en/pub100080.pdf [Accessed: 15 November 2017]

International Organization for Standardization, ISO (2015b) "ISO 9001:2015 Quality Management Systems - Requirements", ISO, Geneva, Switzerland.

International Organization for Standardization, ISO (2015c) "ISO 9001:2015 Quality Management Systems — Fundamentals and vocabulary", ISO, Geneva, Switzerland.

Kagermann, H., Wahlster, W., Helbig, J. (2013) "Recommendations for implementing the strategic initiative INDUSTRIE 4.0", Industrie 4.0 Working Group, Frankfurt am Main, Germany.

Kanji, G. K. (1990) "Total quality management: the second industrial revolution", Total Quality Management, 1(1), pp. 3-12. https://doi.org/10.1080/09544129000000001

Kuo, C.-J., Ting, K.-C., Chen, Y.-C., Yang, D.-L., Chen, H.-M. (2017) "Automatic machine status prediction in the era of Industry 4.0: Case study of machines in a spring factory", Journal of Systems Architecture, 81, pp. 44-53.

https://doi.org/10.1016/j.sysarc.2017.10.007

Lee, J., Bagheri, B., Kao, H. A. (2015) "A Cyber-Physical Systems architecture for Industry 4.0-based manufacturing systems", Manufacturing Letters, 3, pp. 18-23.

https://doi.org/10.1016/j.mfglet.2014.12.001
Lee, J., Kao, H. A., Yang, S. (2014) Service innovation and smart analytics for Industry 4.0 and big data environment. Procedia CIRP, 16 , pp. 3-8. https://doi.org/10.1016/j.procir.2014.02.001

Lu, Y. (2017) "Industry 4.0: A survey on technologies, applications and open research issues", Journal of Industrial Information Integration, 6, pp. 1-10. https://doi.org/10.1016/j.jii.2017.04.005

MacDougall, W. (2013) "Industrie 4.0: Smart Manufacturing for the Future' (20750)", Germany Trade and Invest, Berlin, Reprint May, 2016.

Mrugalska, B., Wyrwicka, M. K. (2017) "Towards Lean Production in Industry 4.0", Procedia Engineering, 182, pp. 466-473. https://doi.org/10.1016/j.proeng.2017.03.135

Pereira, A. C., Romero, F. (2017) "A review of the meanings and the implications of the Industry 4.0 concept", Procedia Manufacturing, 13, pp. 1206-1214. https://doi.org/10.1016/j.promfg.2017.09.032

Qin, J., Liu, Y., Grosvenor, R. (2016) "A Categorical Framework of Manufacturing for Industry 4.0 and Beyond", Procedia CIRP, 52, pp. $173-178$. https://doi.org/10.1016/j.procir.2016.08.005

Rennung, F., Luminosu, C. T., Draghici, A. (2016) "Service Provision in the Framework of Industry 4.0", Procedia - Social and Behavioral Sciences, 221, pp. 372-377.

https://doi.org/10.1016/j.sbspro.2016.05.127

Trappey, A. J. C., Trappey, C. V., Hareesh Govindarajan, U., Chuang, A. C., Sun, J. J. (2017) "A review of essential standards and patent landscapes for the Internet of Things: A key enabler for Industry 4.0", Advanced Engineering Informatics, 33, pp. 208-229. https://doi.org/10.1016/j.aei.2016.11.007

Wang, L., He, J., Xu, S. (2017) "The Application of Industry 4.0 in Customized Furniture Manufacturing Industry", MATEC Web of Conferences, 100, Article No. 03022. https://doi.org/10.1051/matecconf/201710003022

Witkowski, K. (2017) "Internet of Things, Big Data, Industry 4.0 Innovative Solutions in Logistics and Supply Chains Management", Procedia Engineering, 182, pp. 763-769. https://doi.org/10.1016/j.proeng.2017.03.197

Yusof, S. M., Aspinwall, E. (1999) "Critical success factors for total quality management implementation in small and medium enterprises", Total Quality Management, 10(4-5), pp. 803-809. https://doi.org/10.1080/0954412997839

Yusof, S. M., Aspinwall, E. (2000) "Total quality management implementation frameworks: Comparison and review", Total Quality Management, 11(3), pp. 281-294. https://doi.org/10.1080/0954412006801

Zhou, K., Liu, T., Zhou, L. (2015) "Industry 4.0: Towards future industrial opportunities and challenges", In: 2015 12th International Conference on Fuzzy Systems and Knowledge Discovery (FSKD), Zhangjiajie, China, pp. 2147-2152. https://doi.org/10.1109/FSKD.2015.7382284 